\title{
Four Hours Post Endoscopic Retrograde Cholangiopancreatography Serum Amylase as A predictor for Post Endoscopic Retrograde Cholangiopancreatography Pancreatitis
}

\author{
Mohamed F. Hassan', Mohamed M. Eda', Mohamed M. Abdo ${ }^{2 *}$, \\ Bassam M. Salama'
}

'Department of Endemic and Infectious Diseases, and '2Department of Internal Medicine, Faculty of Medicine, Suez Canal University, Egypt

\begin{abstract}
Background: Endoscopic retrograde cholangiopancreatography, uses a combination of both endoscopy and fluoroscopy for diagnosis and treatment of hepatobiliary disorders. ERCP is generally considered to be safe and effective. Post-ERCP complication rates vary widely depending on the complexity of the intervention and the individual patient. Acute pancreatitis is the most common complication following ERCP maneuver, which is reported to occur in 2-10\% of patients overall (varying between $2-4 \%$ in low risk patients up to $8-40 \%$ in high-risk patients). Aim: The study is designed to evaluate the clinical significance of 4-hour post endoscopic retrograde cholangiopancreatography amylase level as an early predictor of post ERCP pancreatitis. This will help to decide when to admit or discharge patient following ERCP, to early diagnose and treat post ERCP pancreatitis and hence spare major hospital resources. Patients and Methods: This study is a prospective cohort study, conducted in the endoscopy unit in Suez Canal university hospital, including adult patients of both sexes eligible for ERCP, excluding patients with pre ERCP pancreatitis, previous ERCP or patients with renal failure. Results: This study included 86 patients candidate for ERCP of whatever indication excluding patients with pre-endoscopic pancreatitis. In this study pancreatitis occurred in 14 patients out of $86(16.3 \%)$. 4 hours serum amylase level was significantly higher in patients with post ERCP pancreatitis than in patients without post ERCP pancreatitis $(P=0.001)$. 4 hours post ERCP serum amylase is a significant predictor for early prediction of occurrence of PEP. Conclusions: Rising of serum amylase 4 hours post endoscopic retrograde cholangiopancreatography above 3.5 ULR is a significant predictor and patient with this level should be admitted and early treated
\end{abstract}

Key Words: ERCP, Pancreatitis, Amylase

\section{Introduction}

Endoscopic retrograde cholangiopancreatography (ERCP) is a technique which use of endoscopy and fluoroscopy for diagno- sis and treatment conditions of the biliary or pancreatic ductal systems. Through the endoscope, the physician can see the inside of the stomach and duodenum, and inject a contrast medium into the ducts in

*Corresponding Author: d_m.abdo2014@yahoo.com 
the biliary tree and pancreas so they can be seen on radiographs ${ }^{(1)}$. ERCP was used primarily for diagnosis and treatment of problems of the bile ducts and main pancreatic duct, including gallstones, inflammatory strictures (scars), leaks (from trauma and surgery), and cancer ${ }^{(1-3)}$. ERCP could be performed for diagnostic and therapeutic reasons, although the development of safer and relatively noninvasive techniques such as magnetic resonance cholangiopancreatography (MRCP) and endoscopic ultrasound (EUS) has meant that ERCP is now rarely performed without therapeutic intent. Because ERCP has a potential risk of severe post ERCP complications than most other endoscopic procedures do, having an appropriate indication for its use is extremely important ${ }^{(4)}$. Acute pancreatitis is the most common complication of ERCP. According to a large, multicenter study the incidence of post- ERCP pancreatitis (PEP) approximately is $6.7 \%$. Although most episodes of pancreatitis following ERCP are mild (about 90\%), a small percentage of PEP (about 10\%) may Complain of moderate or severe pancreatitis need to be admitted for long duration, intensive care unit admission and utilization of major hospital resources; patients of sever PEP have a high morbidity and mortality ${ }^{(5-8)}$. It is of importance that we accurately recognize which patients will develop PEP. Since most ERCP practice is performed on an outpatient basis, early assessment and evaluation of patients can allow early secured discharge of most patients post endoscopic procedures who will not develop PEP or just may develop mild symptoms that will be self-limited and no complications post ERCP. On the other hand, early identification of those patients who may develop moderate or severe PEP help decisions regarding admission to hospital and intensive management ${ }^{(9-11)}$. In addition, early diagnosis helps the use of tar- geted management that has the possibility to prevent or reduce inflammation of pancreas. Therefore, major efforts concentrate on trying to recognize predictors of post-ERCP pancreatitis that help in earlier detection and allow for reducing severity. Serum Amylase increases in reaction to manipulations during ERCP in the majority of patients ${ }^{(12-17)}$. Without pancreatitis, serum amylase levels peak at approximately 90 minutes to approximately 4 hours after ERCP procedure and return around normal levels within 48 hours after ERCP procedure ${ }^{(18-23)}$. Although Serum amylase level is frequently elevated in uncomplicated ERCPs, the speed and degree of elevation is to a great extent seen in patients who develop PEP. Consequently, this study was conducted to assess the value of serum amylase as a potential predictor of PEP(20-25). In a study conducted by Testoni et al., serum amylase and lipase concentrations at 4 hours after ERCP were reported to be useful for predicting or ruling out post-procedure pancreatitis $^{(20)}$.

\section{Subjects and Methods}

This study is a prospective cohort study, conducted in the gastrointestinal endoscopy unit in Suez Canal university hospital, included 86 adult patients of both sexes, presented with either painful or painless obstructive jaundice candidate for ERCP excluding patient with pre endoscopic pancreatitis, or patients with renal impairment. All subjects were subjected to Clinical evaluation: History, Examination: (general and abdominal examinations), ERCP procedure after consent assignment. Post ERCP pancreatitis is defined as the presence of pancreatic-type abdominal pain severe enough to require hospital admission associated with levels of S. amylase 3 times the upper limit of normal occurring within 24 hrs after ERCP. 
1- Before ERCP

History taking including Socio demographic data, indication of ERCP, chronic illnesses, drug history, history of allergy to drugs and contrast dye, previous ERCP, Previous pancreatitis and previous operations.

Clinical examinations: including general and abdominal examinations

Laboratory data including Complete blood count, ALT, AST, alkaline phosphatase, bilirubin, prothrombin time, creatinine, amylase, s. lipase.

Radiological data including Abdominal US, CT or MRCP to determine the cause of obstruction. ERCP procedure was done in gastrointestinal endoscopy unit under general anesthesia in prone or lateral positions and diathermy is connected. The number of cannulation trials, amount of contrast dye, sphincterotomy or precut sphincterotomy, bleeding, stent insertion, ballooning dilatation, stone extractions, radiological diagnosis were recorded

\section{2- After ERCP}

Four hours after ERCP procedure, amylase was measured. While 24 hours post ERCP the following was assessed: complete blood count, ALT, AST, alkaline phosphatase, bilirubin, prothrombin time, creatinine, amylase, lipase. abdominal US or CT was done for patients with complications.
After patient stabilizations, patients were discharged.

\section{Results}

This study was conducted in the endoscopy unit Suez Canal university hospital and included 86 adult patients of both sexes excluding patients with previous ERCP, patients with pre-endoscope pancreatitis and patients with renal failure about $53 \%$ of them were females. Most of their ages were less than 60 years (64\%). Pancreatitis occurred in $16.3 \%$ of patients. The demographic, clinical, laboratory and ERCP findings are shown in the following tables. Most of study populations presented with evidence of extra hepatic biliary obstructions with jaundice either painless obstructive jaundice $54 / 86(62.8 \%)$ or painful obstructive jaundice $32 / 86$ (37.2\%). In this study $14 / 86$ patients (16.3\%) were diagnosed to have post ERCP pancreatitis 24 hours post procedures. The prevalence of hyperamylesemia in both patients with and without pancreatitis revealed that $92.9 \%$ of patients with post ERCP pancreatitis have significantly higher elevation of serum amylase level 4 hours post endoscopic procedure compared to $37.5 \%$ only of patients without post ERCP pancreatitis $(p=0.001)$ (Table 1).

Table 1: prevalence of hyperamylesemia in both patients with and without pancreatitis

\begin{tabular}{|l|c|c|c|c|}
\hline \multirow{2}{*}{$\begin{array}{l}4 \text { hrs post ERCP } \\
\text { serum amylase }\end{array}$} & Post ERCP pancreatitis & \multirow{2}{*}{ total } & \multirow{2}{*}{ P value } \\
\cline { 2 - 3 } & No & Yes & & \\
\hline Above ULN & $27(37.5 \%)$ & $13(92.9 \%)$ & $40(46.5 \%)$ & \multirow{2}{*}{0.001} \\
\hline below ULN & $45(62.5 \%)$ & $1(7.1 \%)$ & $46(53.5 \%)$ & \\
\hline Total & $72(100 \%)$ & $14(100 \%)$ & & \\
\hline
\end{tabular}

ULN= upper limit of normal

Univariate analysis of risk factors of post ERCP pancreatitis including sociodemographic data, pre endoscopic radiological and laboratory results and steps of endoscopic procedure shows a statistically significant associations between the in- creased risk of post-ERCP pancreatitis and pre endoscopic levels of AST and 4 hours post ERCP S. amylase ( $p=0.003,0.000$ respectively) and also with $G B$ radiological findings (Table 2). ROC curve was used to define the best cut off value of the post 
ERCP amylase which was $\geq 338 \mu / L$, with sensitivity of $93.3 \%$, specificity of $94.4 \%$,
PPV of $77.8 \%$, NPV of $98.5 \%$ with diagnostic accuracy of $90.8 \%$ (Fig. 1) and Tables $(3,4)$.

Table 2: Univariate Analysis of Risk Factors for Post-ERCP Pancreatitis in our study

\begin{tabular}{|c|c|c|c|c|c|}
\hline \multirow{2}{*}{\multicolumn{3}{|c|}{ Variable }} & \multicolumn{2}{|c|}{ Post-ERCP pancreatitis } & \multirow[b]{2}{*}{$P$ value } \\
\hline & & & \multirow{2}{*}{$\begin{array}{c}\text { No }(n=72) \\
83.7 \% \\
51.18 \pm 16.76\end{array}$} & $\begin{array}{c}\text { Yes }(n=14) \\
16.3 \%\end{array}$ & \\
\hline \multicolumn{3}{|l|}{ Age (yrs) } & & $44.36 \pm 14.71$ & 0.736 \\
\hline \multirow{2}{*}{ Sex } & \multicolumn{2}{|l|}{ Male } & $39(54.2 \%)$ & $4(28.6 \%)$ & \multirow{2}{*}{0.080} \\
\hline & \multicolumn{2}{|c|}{ Female } & $33(45.8 \%)$ & $10(71.4 \%$ & \\
\hline \multirow[b]{2}{*}{ Complain } & \multicolumn{2}{|c|}{ Biliary Colic } & $28(38.9 \%$ & $4(28.6 \%)$ & \multirow[b]{2}{*}{0.340} \\
\hline & \multicolumn{2}{|c|}{$\begin{array}{l}\text { Obstructive } \\
\text { Jaundice }\end{array}$} & $44(61.1 \%)$ & $10(71.4 \%$ & \\
\hline \multirow{4}{*}{ ERCP Diagnosis } & \multicolumn{2}{|c|}{ Calcular } & $54(75.0 \%)$ & $9(64.3 \%)$ & \multirow{4}{*}{0.465} \\
\hline & \multicolumn{2}{|c|}{ Malignant } & $15(20.8 \%)$ & $4(28.6 \%$ & \\
\hline & \multicolumn{2}{|c|}{ Biliary mud } & $1(1.4 \%)$ & $1(7.1 \%)$ & \\
\hline & \multicolumn{2}{|c|}{ Unknown } & $2(2.8 \%)$ & $0(0.0 \%)$ & \\
\hline \multicolumn{3}{|c|}{ HB (pre endoscopic) } & $12.63 \pm 1.68$ & $11.5357 \pm 1.50$ & 0.954 \\
\hline \multicolumn{3}{|c|}{ TLC (pre endoscopic) } & $8.0333 \pm 3.39$ & $8.21 \pm 3.58$ & 0.899 \\
\hline \multicolumn{3}{|c|}{ PLT (pre endoscopic } & $260.11 \pm 102.94$ & $301.71 \pm 126.06$ & 0.351 \\
\hline \multicolumn{3}{|c|}{ ALT (pre endoscopic } & $141.06 \pm 118.77$ & $124.50 \pm 92.50$ & 0.480 \\
\hline \multicolumn{3}{|c|}{ AST (pre endoscopic) } & $128.75 \pm 90.1$ & $106.86 \pm 35.62$ & 0.003 \\
\hline \multicolumn{3}{|c|}{ T. Bilirubin (pre endoscopic) } & $8.47 \pm 7.11$ & $6.6743 \pm 4.95$ & 0.412 \\
\hline D. Bilirubin (pre e & idoscopic) & & $6.29 \pm 5.79$ & $5.61 \pm 4.55$ & 0.659 \\
\hline PT (pre endoscop & & & $12.43 \pm 1.47$ & $12.46 \pm 2.36$ & 0.084 \\
\hline Amylase (pre enc & oscopic) & & $56.04 \pm 32.07$ & $50.07 \pm 25.80$ & 0.81 \\
\hline Lipase (pre endo & copic) & & $41.03 \pm 24.97$ & $31.13 \pm 20.72$ & 0.38 \\
\hline Creat (pre endos & opic) & & $0.84 \pm 0.21$ & $0.83 \pm 0.46$ & 0.081 \\
\hline & Normal & & $11(15 \cdot 3 \%)$ & $8(57.1 \%)$ & \\
\hline US of GB & $\begin{array}{l}\text { Chronic } \\
\text { calcular } \\
\text { cholycyst }\end{array}$ & & $58(80.6 \%)$ & $5(35.7 \%)$ & 0.002 \\
\hline & removed & & $3(4.2 \%)$ & $1(7.1 \%)$ & \\
\hline U/S CBD & Diameter & & $13.17 \pm 4.27$ & $14.64 \pm 6.48$ & 0.065 \\
\hline & Stones & Yes & $27(37.5 \%)$ & $4(28.6 \%)$ & \\
\hline & & No & $45(62.5 \%)$ & $10(71.4 \%)$ & 0.524 \\
\hline US of liver span & & & $14.07 \pm 2.08$ & $14.93 \pm 1.07$ & 0.060 \\
\hline US of spleen spar & & & $10.76 \pm 2.12$ & $10.93 \pm 2.25$ & $0 . .869$ \\
\hline Cannulation & & & $4.94 \pm 2.63$ & $6.86 \pm 4.19$ & 0.043 \\
\hline amount of contra & & & $16.27 \pm 4.74$ & $15.64 \pm 3.41$ & 0.101 \\
\hline Sobincterotomy & Yes & & $70(97.2 \%)$ & $14(100 \%)$ & 0.528 \\
\hline 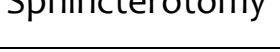 & No & & $2(2.8 \%)$ & $\mathrm{O}(0 \%)$ & $0 . .5<0$ \\
\hline Stent insertion & Yes & & $54(75.0 \%)$ & $10(71.4 \%)$ & 0.770 \\
\hline 1 & No & & $18(25.0 \%)$ & $4(28.6 \%)$ & $0.1 / 9$ \\
\hline Balloon & Yes & & $37(51.4 \%)$ & $7(50.0 \%)$ & \\
\hline sweeping & No & & $35(48.6 \%)$ & $7(50.0 \%)$ & 0.924 \\
\hline Stone & Yes & & $28(38.9 \%)$ & $6(42.9 \%)$ & 0.781 \\
\hline Extraction & No & & $44(61.1 \%)$ & $8(57.1 \%)$ & 1... \\
\hline Amyase (4h Post & perative) & & $133.06 \pm 140.53$ & $641.43 \pm 624.70$ & $<0 . .000$ \\
\hline
\end{tabular}




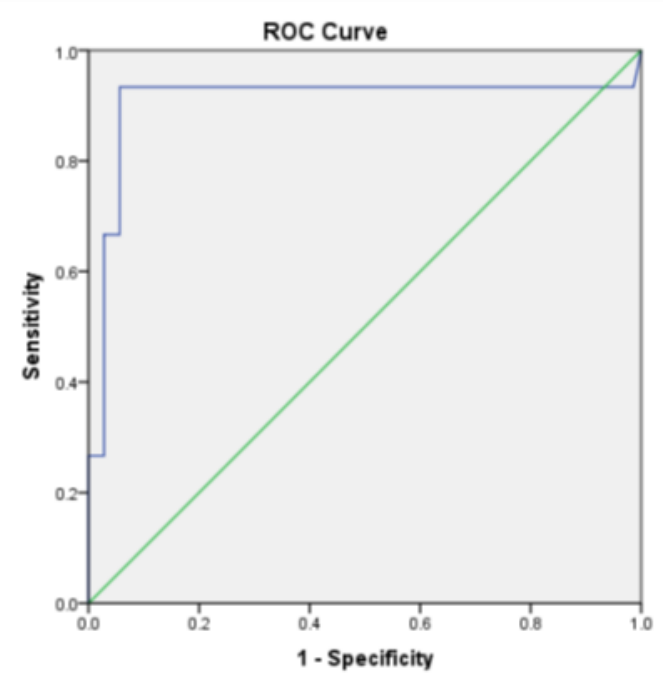

Figure 1: ROC curve for defining the best cut off value of the post ERCP amylase

\section{Discussion}

Endoscopic retrograde cholangiopancreatography is a very important maneuver in the diagnosis and management of different pancreato-biliary diseases. Despite all the advances and improvement in ERCP techniques, post-ERCP acute pancreatitis remains the most feared and common complication, being associated with high morbidity and mortality ${ }^{(26-28)}$. We aimed in our study to evaluate the clinical significance of 4-hour post endoscopic retrograde cholangiopancreatography amylase level as an early predictor of post ERCP pancreatitis. This study was conducted in endoscopy unit Suez Canal University hospital and included 86 adult patients of both sexes, excluding patients with pre endoscopic pancreatitis, history of previous ERCP and patients with renal failure, range of age in study population was between the $21-83$ years, mean of $50.07 \pm$ 16.55 years, most of their ages were less than 60 years (64\%), about $53.5 \%$ of them were females, about $89.5 \%$ of them were married, and about $67.5 \%$ of them lived in urban area. In this study post ERCP pancreatitis occurred in 14 patients out of 86 patients (16.3\%). However., in a study in ElMansoura university the overall, PEP occurred in $10.2 \%$ of patients ${ }^{(27)}$. Moreover in a meta-analysis of 108 randomized, controlled trials (RCTs) an overall incidence of post ERCP pancreatitis is $9.7 \%$, with a mortality rate of $0.7 \%$ was reported ${ }^{(11)}$.

Table 3: statistical significance of 4 hours post ERCP amylase level in prediction of acute pancreatitis at cut off point $\geq 338$

\begin{tabular}{|l|l|l|}
\hline Test & Value & P Value \\
\hline Sensitivity & $93.3 \%(95 \% \mathrm{Cl}: 68.1 \%-99.8 \%)$ & $<0.001$ \\
\hline Specificity & $94.4 \%(95 \% \mathrm{Cl}: 86.2 \%-98.4 \%)$ & $<0.001$ \\
\hline Accuracy & $90.8 \%(95 \% \mathrm{Cl}: 78.2 \%-100 \%)$ & $<0.001$ \\
\hline St. error & 0.64 & ---- \\
\hline Positive predictive value & $77.8 \%(95 \% \mathrm{Cl}: 57.2 \%-90.2 \%)$ & $<0.001$ \\
\hline Negative predictive value & $98.5 \%(95 \% \mathrm{Cl}: 91 \%-99.8 \%)$ & $<0.001$ \\
\hline Positive likelihood ratio & 16.57 & ---- \\
\hline Negative likelihood ratio & 0.07 & ---- \\
\hline
\end{tabular}


Table 4: $4 \mathrm{~h}$ post-ERCP serum amylase utility in predicting post-ERCP pancreatitis

\begin{tabular}{|c|c|c|c|c|c|}
\hline Amylase & Sensitivity & Specificity & PPV & NPV & Positive likelihood ratio \\
\hline$>2.5$ & $92.9 \%$ & $87.5 \%$ & $59 \%$ & $98.5 \%$ & 7.4 \\
\hline$>3.5$ & $92.9 \%$ & $93.1 \%$ & $72.8 \%$ & $98.5 \%$ & 13.4 \\
\hline$>4.5$ & $64.3 \%$ & $95.8 \%$ & $75 \%$ & $93.2 \%$ & 15.4 \\
\hline$>5$ & $57 \%$ & $97.2 \%$ & $80 \%$ & $92.16 \%$ & 20.5 \\
\hline
\end{tabular}

In our study about $92.9 \%$ of patients with post ERCP pancreatitis have elevation of serum amylase level 4 hours post endoscopic procedure compared to $37.5 \%$ only of patients without post ERCP pancreatitis and this is statistically significant. In this study univariate analysis of risk factors of post ERCP pancreatitis including sociodemographic, indications, pre endoscopic laboratory and radiological finding and steps of endoscopic procedure and also 4hours post ERCP serum amylase revealed that statistically significant associations between an increased risk of post-ERCP pancreatitis and pre endoscopic levels of AST, and 4 hours post ERCP serum level of amylase. In our study 4hours serum amylase level was significantly higher in patients with post ERCP pancreatitis than in patients without post ERCP pancreatitis ( $P$ value 0.001 ) and this indicate that 4hours serum amylase level is a good predictor of post ERCP pancreatitis .Moreover it was concluded that the 4-h post-ERCP serum amylase level was found to be a useful means of predicting pancreatitis both after diagnostic ERCP and after therapeutic ERCP in a large retrospective study in a single center and this support our results. Also Testoni et al., in their study of twenty-four-hour Serum amylase predicting pancreatic reaction after endoscopic sphincterotomy showed that serum amylase assessment four hours after sphincterotomy is a reliable, cost-effective follow-up and minimizes the likelihood of underestimating the risk of post-procedure pancreatic reaction ${ }^{(29-31)}$. In our study according to ROC curve anal ysis of 4 hours post ERCP amylase level, it was found that the cut off value of 4 hours post ERCP serum amylase level is $>338 \mathrm{IU} / \mathrm{L}$. at this amylase level more than or equal 338 the incidence of acute pancreatitis increases with sensitivity $93.3 \%$, specificity $94.4 \%$,positives predictive value (PPV) $77.8 \%$, and negative predictive value (NPV) 98.5 with p-value <0.00. In another study conducted by Okasha et al., in Cairo university in 2015, they found that ROC curve analysis it was found that the cut off value of 4 hours post ERCP serum amylase level is $>260 \mathrm{IU} / \mathrm{L}$. at this amylase level more than or equal 260 the incidence of acute pancreatitis increases with a sensitivity of $88.89 \%$, specificity of $94.51 \%$, positive predictive value (PPV) of $61.50 \%$, negative predictive value (NPV) of $98.9 \%$ and accuracy of $92 \%$. p-value $<0.001^{(26)}$. In this study 4 hours post ERCP serum amylase level is significant predictor of post ERCP pancreatitis at cut off value 3.5 ULR with sensitivity $92.9 \%$, specificity $93.1 \%$, positive predictive value $72.8 \%$, negative predictive value $98.5 \%$ and Positive likelihood ratio 13.4. In a retrospective study Sutton et al. also studied the significance of post ERCP serum amylase level in prediction of increase risk of acute pancreatitis and they put a cut off value of 2.5 of upper limit range in case of pancreatogram with sensitivity $80 \%$ and specificity $80.4 \%$ and a cut off value of 5 of ULR in case of no pancreatogram with sensitivity $100 \%$ and specificity $91.8 \%{ }^{(2-19)}$. In a study of 4 hours post ERCP serum amylase level as predictor of post ERCP pancreatitis in Australia the performance of the test at various cut-off 
values, illustrating optimal sensitivity at a cutoff value 1.5-fold the normal level, and optimal specificity at a cut-off value threefold the normal level ${ }^{(6-8)}$. In one study the optimal cutoff values for amylase were five times $(625 \mathrm{IU} / \mathrm{I})$ the upper limit of the normal range ${ }^{(23)}$.

\section{Conclusion}

We can conclude that 4 hours post ERCP serum amylase is a significant predictor for early prediction of occurrence of PEP. Rising of serum amylase 4 hours post ERCP ABOVE 3.5 ULR is significant predictor and patient with this level should be admitted and management of PEP should be rapidly started

\section{References}

1. Adler DG, Baron TH, Davila RE, Egan J, Hirota WK, Leighton JA, Qureshi W, Rajan E, Zuckerman MJ, Fanelli R, WheelerHarbaugh J, Faigel DO. the role of ERCP in diseases of the biliary tract and the pancreas.gastrointestinal endoscopy .2005;(4):1-8.

2. CheonYK, Cho KB,Watkins JL ,McHenry LM,FogelEL,Sherman S, Lehman GA. Frequency and severity of post-ERCP pancreatitis correlated with extent of pancreatic ductal opacification. Gastrointestinal endoscopy 2007;(3): 385-393.

3. Yaghoobi M, Pauls Q, Durkalski V, et al. Incidence and predictors of post-ERCP pancreatitis in patients with suspected sphincter of Oddi dysfunction undergoing biliary or dual sphincterotomy: results from the EPISOD prospective multicenter randomized sham-controlled study.2015; Endoscopy 47(10): 884-890.

4. Lopes TL and Baron TH. Endoscopic retrograde cholangiopancreatography in patients with rouxen- $Y$ anatomy.2011 J Hepatobiliary Pancreat Sci (2011) 18:332338.

5. SzaryN. and Al-Kawas F H. Complications of endoscopic retrograde cholangiopancreatography: how to avoid and manage them; Gastroenterology \& herpetology2013; (8):496-504.

6. Freeman $M L$, Nelson $D B$, Sherman $S$, Haber GB, Herman ME, Dorsher PJ, Moore JP, Fennerty MB, Ryan ME, Shaw MJ, Lande JD, Pheley AM. Complications of endoscopic biliary sphincterotomy.New England Journal of Medicine 1996;(13): 909-919.

7. Thaker AM, Mosko JD, Berzin TM. Postendoscopic retrograde cholangiopancreatography pancreatitis. Gastroenterol Rep 2015; (1): 32-40.

8. Kochar B ,.Akshintala VS, Afghani E , Elmunzer J ,Kim KJ, Lennon AM, Khashab MA,.Kalloo AN. Incidence, severity, and mortality of post-ERCP pancreatitis. systematic review by using randomized, controlled trials. Gastrointestinal endoscopy 2015;(1): 143-149. e149

9. Cotton PB, Garrow DA, Gallagher MJ,Romagnuolo J. Risk factors for complications after ERCP: a multivariate analysis of 11,497 procedures over 12 years." Gastrointestinal endoscopy 2009;(1): 80-88.

10. Olsson G, Arnelo U, Swahn F, Törnqvist $B$, Lundell L, Enochsson L. The HOUSE classification: a novel endoscopic retrograde cholangiopancreatography (ER$\mathrm{CP})$ complexity grading scale." BMC gastroenterology 2017;(1): 38

11. Anderson $A M$, Fisher $L$, Jain $R$, Jain $R$, Evans JA, Appalaneni V, Ben-Menachem T, Cash BD, Decker GA. Complications of ERCP." Gastrointestinal endoscopy 2012;(3): 467-473.

12. Freeman ML, Guda NM. Prevention of post-ERCP pancreatitis: a comprehensive review." Gastrointestinal endoscopy 2004;(7): 845-864.

13. Halttunen J, Meisner S, Aabakken L, et al. Difficult cannulation as defined by a prospective study of the Scandinavian Association for Digestive Endoscopy (SADE) in 907 ERCPs.Scandinavian journal of gastroenterology 2014;(6): 752758.

14. Tse F, Yuan Y, Moayyedi P, Leontiadis GI. Guidewire-assisted cannulation of the 
common bile duct for the prevention of post-endoscopic retrograde cholangiopancreatography (ERCP) pancreatitis. " Cochrane Database Syst Rev 2012.

15. Abdel Aziz AM and Lehman GA. Pancreatitis after endoscopic retrograde cholangio-pancreatography. WJG: 2007; (19): 2655-2668.

16. Sultan S. and Baillie J. What are the predictors of post-ERCP pancreatitis, and how useful are they. Jop 2002;(6): 188194.

17. He QB, Xu T, Wang J, Li YH, Wang L, Zou $X P$. Risk factors for post-ERCP pancreatitis and hyperamylasemia: A retrospective single-center study. Journal of digestive diseases 2015(8): 471-478.

18. Chen CC, Wang SS, Lu RH, Lu YF, Chang FY, Lee SD. Early changes of serum proinflammatory and anti-inflammatory cytokines after endoscopic retrograde cholangiopancreatography. Pancreas 2003(4): 375-380.

19. Gottlieb K, Sherman S, Pezzi J, Esber E, Lehman GA. Early recognition of postERCP pancreatitis by clinical assessment and serum pancreatic enzymes." American Journal of Gastroenterology 1996;(8): 1553-1557.

20. Testoni PA, Caporuscio S, Bagnolo F, LellaF. Twenty-four-hour serum amylase predicting pancreatic reaction after endoscopic sphincterotomy. Endoscopy1996;(02): 131-136.

21. Thomas PR, and Sengupta S. Prediction of pancreatitis following endoscopic retrograde cholangiopancreatography by the 4-h post procedure amylase level. Journal of gastroenterology and hepatology 2001;(8): 923-926.

22. Christoforidis E, Goulimaris I, Kanellos I, Tsalis K, Demetriades C, Betsis D. PostERCP pancreatitis and hyperamylasemia: patient-related and operative risk factors. Endoscopy 2002;(04): 286-292.

23. Sutton VR, Hong MK, Thomas PR. Using the 4-hour Post-ERCP amylase level to predict post-ERCP pancreatitis. JOP. Journal of the Pancreas2011;(4): 372-376.

24. Kapetanos D, Kokozidis G, Kinigopoulou $P$ et al. The value of serum amylase and elastase measurements in the prediction of post-ERCP acute pancreatitis. Hepato-gastroenterology 2007 ; 74): 556-560.

25. Chen JJ, Wang XM, Liu XO, et al. Risk factors for post-ERCP pancreatitis: a systematic review of clinical trials with a large sample size in the past 10 years. European journal of medical research 2014;(1): 26.

26. Okasha HH. Hashem A and El kassar HM. The Significance of the 4-Hours PostERCP Serum Amylase Level to Predict Post-ERCP Pancreatitis. Med. J. Cairo Univ2015; (2): 73-77.

27. El Nakeeb A, El Hanafy E, Salah T, Atef E, Hamed H, Sultan AM, Kandil T. Postendoscopic retrograde cholangiopancreatography pancreatitis: Risk factors and predictors of severity. World journal of gastrointestinal endoscopy, 2016; (19), 709.

28. Schulman AR, Abougergi MS, and Thompson CC. Assessment of the July effect in post-endoscopic retrograde cholangiopancreatography pancreatitis: Nationwide Inpatient Sample. World journal of gastrointestinal endoscopy, 2017;(7), 296.

29. Katsinelos P, Lazaraki G, Chatzimavroudis G, Gkagkalis S, Vasiliadis I, Papaeuthimiou A, Kountouras J. Risk factors for therapeutic ERCP-related complications: an analysis of 2,715 cases performed by a single endoscopist. Annals of gastroenterology, 2014(1), 65

30. Makmun D, Abdullah M, Syam A F, Fauzi A. Post-ERCP pancreatitis and its related factors: A prospective study in Cipto Mangunkusumo National General Hospital. J digest Endoscopy 2015: 6(2); 163168.

31. Testoni P, Caporuscio S, Bagnolo F, Lella F. Serum amylase measured four hours after endoscopic sphincterotomy is a reliable predictor of post-procedure pancreatitis. Endoscopy.1999;31(2):131-136. 